\title{
Clinical Analysis
}

\section{Trocar Site Hernia after Laparoscopic Colectomy}

\author{
Kazuhiro SAKAMOTO, Yoshihiko TASHIRO, Seigo ONO, Kiichi SUGIMOTO, \\ Shun ISHIYAMA, Yukihiro YAGINUMA, Hiromitsu KOMIYAMA, Yutaka KOJIMA, \\ Masanobu TANAKA, Michitoshi GOTO, Hironobu SENGOKU and Yuichi TOMIKI
}

Department of Coloproctological Surgery, Juntendo University, School of Medicine

\begin{abstract}
Purpose Trocar site hernia (TSH) is an uncommon sequela of laparoscopic procedures. In this retrospective study, we determined the incidence of TSH and investigated the associated risk factors in patients undergoing laparoscopic colectomy (LC).

Subjects Three hundred and ten patients who underwent LC for colorectal disease between December 1993 and February 2008 in our hospital.

Results In this series, the incidence of TSH was 1.6\% ( 5 patients). There were no differences in age, gender, body mass index (BMI), tumor site or diabetes mellitus between the TSH and non-TSH groups. Comparison between patients with and without TSH revealed no differences in trocar size, type or site. However, there were significant differences in drain placement and fascial closure at the trocar insertion site after trocar removal. All TSH occurred in the left lower abdominal region, where an abdominal trocar had been placed for sigmoid or rectosigmoid colon cancer surgery and a drain had been placed after the trocar removement. The trocar diameter was $10-\mathrm{mm}$ in 3 and $5-\mathrm{mm}$ in 2 patients. Surgical treatment was provided to two patients with earlyonset TSH and incarceration of the small intestine, and to one with late-onset TSH patient and abdominal pain. In the other two patients, who had omental hernias after drain removal, the fascias at the trocar sites were closed under local anesthesia.
\end{abstract}

Received: October 28, 2008/Accepted: December 27, 2008

Correspondence to: Kazuhiro Sakamoto

Department of Coloproctological Surgery, Juntendo University, School of Medicine, 2-1-1 Hongo, Bunkyoku, Tokyo 113-8421, Japan
Conclusion The range of intraoperative port movement and drain placement through a port site, which involve dilatation of the trocar orifice or disturbance of the fascial closure, are risk factors for the occurrence of TSH.

Key words: laparoscopic colectomy, trocar site hernia

\section{Introduction}

Trocar site hernia (TSH), an uncommon sequela, is a type of incisional hernia encountered after laparoscopic procedures. The incidence of TSH reportedly ranges from $0.65 \%$ to $2.8 \%{ }^{11}$. Some authors advocate closure of the fascia after withdrawal of a trocar 10$\mathrm{mm}$ or more in diameter ${ }^{2.3}$. However, others have reported that there is no need for routine fascial closure of all large trocar sites in every patient ${ }^{4,5}$. We sought to determine the incidence of TSH and to investigate the associated risk factors in patients undergoing laparoscopic colectomy (LC).

\section{Material and Methods}

We retrospectively reviewed the clinical records of 310 consecutive patients who underwent LC for colorectal disease between December 1993 and February 2008 in our hospital. For LC, pneumoperitoneum was created after a supra or infra umbilical blunt trocar had been inserted using an open technique. Additional trocars were appropriately placed in the left or right, upper or lower quadrant (LUQ, RUQ, LLQ, RLQ), such that a total of four or five trocars were placed. Bladed trocars were used in patients undergoing LC before December 2002 and radially expanding trocars (VersaStep $^{\mathrm{TM}}$, Covidience, Norwalk, CT) were used thereafter. At the first port site 
Trocar site hernia after laparoscopic colectomy

Table 1 Characteristics of patients with and without trocar site hernia

\begin{tabular}{lccc}
\hline & $\begin{array}{c}\text { TSH } \\
(\mathrm{n}=5)\end{array}$ & $\begin{array}{c}\text { Non-TSH } \\
(\mathrm{n}=305)\end{array}$ & p-Value \\
\hline Age (years) median (range) & $58(52-70)$ & $63(28-88)$ & 0.578 \\
Gender (Female / Male) & $3 / 2$ & $110 / 194$ & 0.543 \\
BMI (kg/m²) median (range) & $19.5(14.3-25.4)$ & $23.0(16.9-32.5)$ & 0.242 \\
Diabetes mellitus & $0 / 5$ & $20 / 285$ & 0.554 \\
Steroid use & $0 / 5$ & $4 / 301$ & 0.797 \\
Diagnosis(Malignant/ Benign) & $5 / 0$ & $278 / 27$ & 0.486 \\
Tumor site (C-A, T, D, S-RS, R) & $0 / 0 / 0 / 5 / 0$ & $65 / 27 / 19 / 154 / 40$ & 0.306 \\
\hline
\end{tabular}

TSH : trocar site hernia, BMI : body mass index, C : Cecum, A : Ascending colon, $\mathrm{T}$ : Transverse colon, D : Descending colon, S : Sigmoid colon,

$\mathrm{RS}$ : Rectosigmoid colon, $\mathrm{R}$ : Rectum

Table 2 Characteristics of trocars in the groups with and without trocar site hernia

\begin{tabular}{lccc}
\hline & $\begin{array}{c}\text { Trocar with TSH } \\
(\mathrm{n}=5)\end{array}$ & $\begin{array}{c}\text { Trocar without TSH } \\
(\mathrm{n}=1393)\end{array}$ & p-Value \\
\hline Size (5mm / 10-12mm) & $2 / 3$ & $559 / 834$ & 0.681 \\
Type (Non-Bladed / Bladed) & $2 / 3$ & $1081 / 312$ & 0.079 \\
Site (Umbilical area / Others ) & $0 / 5$ & $291 / 1102$ & 0.551 \\
Drain (+ /-) & $5 / 0$ & $280 / 1113$ & $<0.001$ \\
Fascial closure (+ /-) & $0 / 5$ & $777 / 616$ & 0.017 \\
\hline
\end{tabular}

$\mathrm{TSH}$; trocar site hernia, Drain; drain placement through trocar site

around the umbilical area, the fascia was closed with sutures. Fascial defects of 10 -mm or larger at the port site were generally closed with a single suture. We used closure devices (Endoclose ${ }^{\mathrm{TM}}$, Covidience), if necessary, for obese patients. However, the fascia at 5-mm port sites was not closed.

All patients were examined 2 or 3 weeks postoperatively and thereafter at 2- or 3-month intervals for the first year. Moreover, patients who underwent LC for colorectal cancer were followed up at 3- or 6-month intervals. Statistical analysis of the results was performed using the Social Science Statistical Program (SPSS ver. 16.0, SPSS Japan Inc., Tokyo, Japan). The $\chi^{2}$-test, Fisher's exact test or Mann-Whitney test was used to determine the statistical significance of differences between the two groups. The level of significance was set at $\mathrm{p}<0.05$.

\section{Results}

In this series of $310 \mathrm{LC}$, the incidence of TSH was $1.6 \%$ ( 5 patients). The characteristics of patients with and without TSH are summarized in Table 1. There were no differences in age, gender, body mass index (BMI) or tumor site between the two groups. Neither diabetes mellitus nor steroid use was present in the TSH group. There were no infections of the trocar site in either group.

In these 310 patients, there were a total of 51312 $\mathrm{mm}$ trocar sites, $20011-\mathrm{mm}$ trocar sites, 124 10-mm trocar sites and 5615 -mm trocar sites. There were 5 TSH in a total of 1398 trocar sites, for an incidence of $0.36 \%$. All 5 TSH occurred at the drain site which had been created through the trocar. Two occurred at sites for the placement of 5-mm radially expanding trocars. There were no differences in trocar size, type or site between the two groups. However, there were significant differences in drain placement and fascial closure after trocar removal (Table 2 ).

The characteristics of TSH patients are summarized in Table 3 . All TSH occurred in the left lower quadrant, where an abdominal trocar had been inserted for sigmoid or rectosigmoid colon cancer. The trocar diameter was $10-\mathrm{mm}$ in 3 and $5-\mathrm{mm}$ in 2 patients.

According to TSH classification ${ }^{1)}$, there were 2 patients with early-onset type, one with late-onset type and two with special type TSH. Two early-onset and one late-onset patient underwent surgery. Two patients with early-onset type complained of nausea and vomiting after the operation, and were examined by abdominal CT scan (Fig. 1). As an incarcerated loop of the small intestine in the left lower 
Table 3 Characteristics of patients with trocar site hernia

\begin{tabular}{|c|c|c|c|c|c|c|c|c|c|c|c|c|c|c|}
\hline \multirow{2}{*}{ Case } & \multirow{2}{*}{ Age } & \multirow{2}{*}{ Gender } & \multirow{2}{*}{$\begin{array}{c}\text { Op. } \\
\text { (year) }\end{array}$} & \multirow{2}{*}{ Diag. } & \multirow{2}{*}{$\mathrm{BMI}$} & \multicolumn{2}{|c|}{ Comorbidity } & \multicolumn{4}{|c|}{ Trocar } & \multirow{2}{*}{$\begin{array}{l}\text { Herniated organ } \\
\text { (Fascia defect) }\end{array}$} & \multirow{2}{*}{$\begin{array}{l}\text { Time from 1st } \\
\text { operation until } \\
\text { symptoms }\end{array}$} & \multirow{2}{*}{ Treament } \\
\hline & & & & & & $\mathrm{DM}$ & Others & Size & Type & Site & Drain & & & \\
\hline 1 & 54 & $F$ & 2001 & $\mathrm{RS} / \mathrm{Ca}$ & 19.3 & $(-)$ & $(-)$ & $10 \mathrm{~mm}$ & Bladed & LLQ & $(+)$ & $\begin{array}{l}\text { Protrusion of } \\
\text { omentum } \\
(10 \mathrm{~mm})\end{array}$ & 7 days & $\begin{array}{l}\text { Fascial } \\
\text { closure }\end{array}$ \\
\hline 2 & 65 & M & 2002 & $\mathrm{RS} / \mathrm{Ca}$ & 25.2 & $(-)$ & $(-)$ & 10 & Bladed & LLQ & $(+)$ & $\begin{array}{l}\text { Incarceration of } \\
\text { small intestine } \\
(15 \mathrm{~mm})\end{array}$ & 13 days & $\begin{array}{l}\text { Bowel } \\
\text { resection }\end{array}$ \\
\hline 3 & 52 & $F$ & 2002 & $\mathrm{~S} / \mathrm{Ca}$ & 25.4 & $(-)$ & $(-)$ & 10 & Bladed & LLQ & $(+)$ & $\begin{array}{l}\text { Incarceration of } \\
\text { small intestine } \\
(15 \mathrm{~mm})\end{array}$ & 14 days & $\begin{array}{l}\text { Bowel } \\
\text { resection }\end{array}$ \\
\hline 4 & 70 & M & 2004 & $\mathrm{~S} / \mathrm{Ca}$ & 14.3 & $(-)$ & $(-)$ & 5 & $\begin{array}{c}\text { Non } \\
\text { Bladed }\end{array}$ & LLQ & $(+)$ & $\begin{array}{l}\text { Protrusion of } \\
\text { omentum } \\
(7 \mathrm{~mm})\end{array}$ & 6 days & $\begin{array}{l}\text { Fascial } \\
\text { closure }\end{array}$ \\
\hline 5 & 58 & $F$ & 2005 & $\mathrm{~S} / \mathrm{Ca}$ & 19.5 & $(-)$ & $\begin{array}{c}\text { Amyloidosis } \\
\mathrm{RF}\end{array}$ & 5 & $\begin{array}{l}\text { Non } \\
\text { Bladed }\end{array}$ & LLQ & $(+)$ & $\begin{array}{l}\text { Protrusion of } \\
\text { omentum } \\
(10 \mathrm{~mm})\end{array}$ & 10 months & $\begin{array}{l}\text { Fascial } \\
\text { closure }\end{array}$ \\
\hline
\end{tabular}

BMI ; body mass index, DM ; diabetes mellitus, Drain; drain placement through trocar site

$\mathrm{RS} / \mathrm{Ca}$ : Rectosigmoid colon cancer, S/Ca : Sigmoid colon cancer, RF ; renal failure, LLQ; left lower quadrant

abdominal 10-mm trocar site was recognized at laparoscopy, a segment of the small intestine was resected and the fascial defect was repaired by an open procedure in both cases (Fig. 2 ). As protrusion of the omentum after drain removal occurred in two patients classified as having special type TSH, fascial closure of the trocar site was performed under local anesthesia. In one late-onset patient, a hernia sac at the trocar site was resected and the fascia was closed 10 months after LC, to ameliorate abdominal pain.

\section{Discussion}

TSH, an uncommon sequela, is a type of incisional hernia encountered after laparoscopic procedures. The incidence of TSH reportedly ranges from $0.65 \%$ to $2.8 \%^{1}$. The average incidence in most published articles is approximately $1 \%$. Tonouchi et al. ${ }^{1)}$ classified TSH into 3 types. The early-onset type occurs immediately after surgery, indicating dehiscence of the anterior fascia plane, posterior fascial plane and peritoneum. The late-onset type occurs several months after the operation, indicating dehiscence of the anterior and posterior fascial planes. The hernia sac of late-onset type involves the peritoneum. The special type indicates dehiscence of the entire abdominal wall. Our TSH patients were classified as having the early-onset, late-onset type and special type in two, one and two cases, respectively.

According to previous reports, the pathogenesis of
TSH is considered to involve not only host factors, but also technical factors such as trocar size and type, the location of the trocar site and fascial closure at the trocar site.

Patient comorbidities such as obesity, infections, and diabetes mellitus, as well as factors including gender and steroid use, can also influence the incidence of TSH. Leibl et al. ${ }^{6)}$ described that $90 \%$ of patients with TSH had comorbidities such as wound infections, diabetes mellitus and obesity, although none of these factors was statistically significant. Our data are consistent with theirs, i.e., differences in gender, obesity and diabetes mellitus between the TSH and non-TSH groups did not reach statistical significance. However, of the two patients with omental hernias at the 5 -mm trocar site, one had amyloidosis and chronic renal failure, and the other was underweight (BMI : 14.3). Such chronic diseases, including poor general condition, are suggested to affect musculature strength and the abdominal wall fascia.

Since we encountered two Richter hernias, where the drain had been inserted through the trocar site, we changed from a $10-\mathrm{mm}$ trocar site to a 5 -mm trocar site. Subsequently, we encountered no further Richter hernias, though two omental hernias were identified at 5-mm trocar sites. There is reportedly a significant association between the frequency of TSH and increasing size of the applied trocars ${ }^{2,7}$. Kadar et al. ${ }^{8)}$ reported an incidence of $0.23 \%$ in asso- 


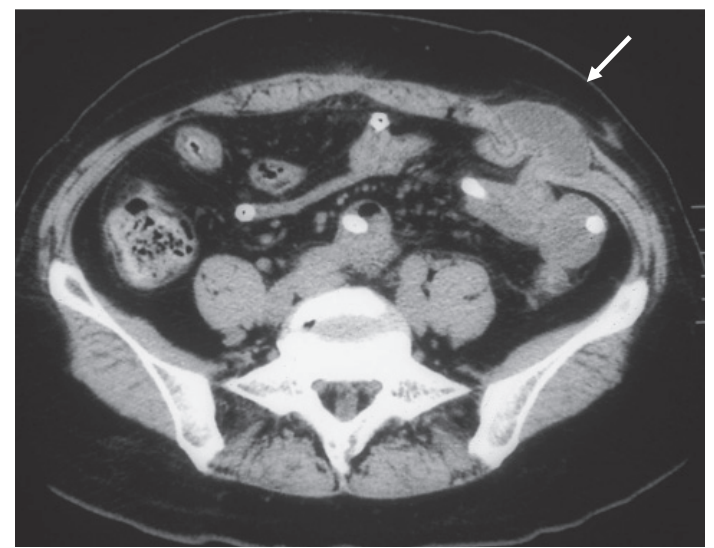

Fig. 1 CT showing a small bowel herniation in Case 3 (arrow) .

ciation with the application of 10 -mm trocars, rising to $3.1 \%$ in patients in whom $12-\mathrm{mm}$ trocars were used.

It is rare for TSH to occur at a 5 -mm trocar site ${ }^{9}$. In 23 case reports, $10-\mathrm{mm}$ or larger trocars were used in 18, an 8-mm trocar in one and a 5-mm trocar in 5 cases $^{1)}$. Therefore, it has been previously recommended to close any fascial defect greater than or equal to a $10-\mathrm{mm}$ trocar site. However, some authors have suggested that there is no need for routine fascial closure of $10-\mathrm{mm}$ or larger trocar sites in every patient $t^{4.5)}$. Mahmoud et al. $^{5}$ ) reported that THS was not detected by physical examination or by ultrasound at 810 sites for $10-\mathrm{mm}$ bladed trocars without fascial closure, which had been created for laparoscopic Nissen fundoplication. Non-bladed trocars may not necessitate closure of the fascia, because they are considered to be less traumatic to the abdominal wall. Johnson et al. ${ }^{4)}$ described no hernias were identified in 747 patients undergoing Roux-en$\mathrm{Y}$ gastric bypass surgery for morbid obesity at any of the $12-\mathrm{mm}$ or 5 -mm radially expanding trocar sites. These radially expanding trocars have no tissue-cutting features and have the perceived advantage of causing less tissue damage and subsequent wound complications. The defects caused by radially expanding trocars have been shown to be approximately $50 \%$ narrower than those left by tissue-cutting trocars ${ }^{10)}$.

Stretching the trocar site might contribute to the occurrence of TSH. Boldó et al. ${ }^{11)}$ reported that the use of large meshes may be a risk for the occur-

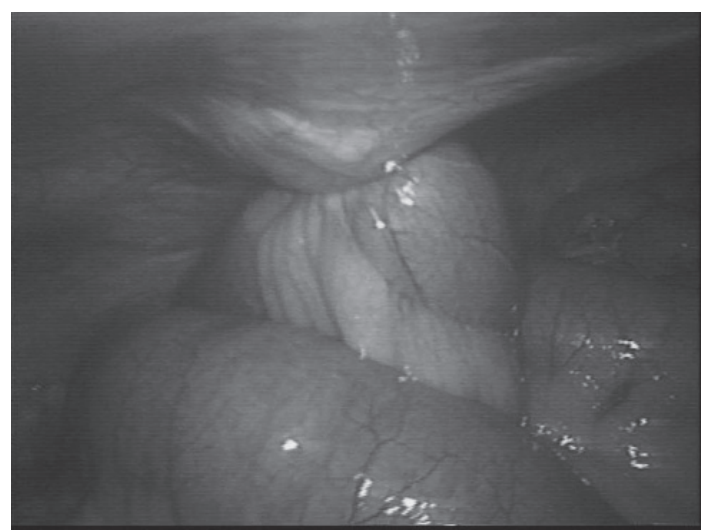

Fig. 2 Intraoperative picture showing herniation of a loop of small intestine through the left lower 10$\mathrm{mm}$ trocar site in Case 2.

rence of TSH in laparoscopic ventral hernia repair (LVHR) because of the trocar orifice dilatation required for introducing a large mesh. Drain placement through a trocar site may affect dilatation of the trocar orifice, in the same way as mesh introduction for LVHR.

Port movement following the manipulation of laparoscopic forceps may be different for each port placement site. In our study, all TSH were located in the left lower quadrant where an abdominal trocar was created for sigmoid or rectosigmoid colon cancer. We chose the left lower quadrant trocar site to allow the widest range of intraoperative trocar movement for the usual 5 trocars used for sigmoid or rectosigmoid colon cancer. Moreover, even small trocar sites may become enlarged with extensive manipulation, including dislodgement and reinsertion ${ }^{12}$. Drain placement after extensive manipulation may disturb normal healing at the port-site wound and delay fascial closure.

To prevent TSH formation at a drain site after removal, it would be best to use a 5 -mm port site for drainage, and to create a new oblique drain insertion for patients who have risk factors in the abdominal muscle and fascia, such as those who are underweight or in poor general condition.

\section{Conclusions}

The range of intraoperative port movement and drain placement through a port site, which involve dilatation of the trocar orifice or disturbance of the 
fascial closure, are risk factors for TSH formation.

\section{References}

1) Tonouchi $\mathrm{H}$, Ohmori $\mathrm{Y}$, Kobayashi $\mathrm{M}$, et al : Trocar site hernia. Arch Surg 139 : 1248-1256, 2004

2) Boughey JC, Nottingham JM, Walls AC : Richter's hernia in the laparoscopic era : four case reports and review of the literature. Surg Laparosc Endosc Percutan Tech $13: 55-58,2003$

3) Kouba EJ, Hubbard JS, Wallen E, et al : Incisional hernia in a 12-mm non-bladed trocar site following laparoscopic nephrectomy. Urol Int 79 : 276-279, 2007

4) Johnson WH, Fecher AM, McMahon RL, et al : VersaStepTM trocar hernia rate in unclosed fascial defects in bariatric patients. Surg Endsc 20 : 1584-1586, 2006

5) Mahmoud HY, Ustuner EH, Sozener U, et al : Cannula site insertion technique prevents incisional hernia in laparoscopic fundoplication. Surg Laparosc Endosc Percutan Tech 17 : 267-270, 2007

6) Leibl BJ, Schmedt CG, Schwarz J, et al : Laparoscopic surgery complications associated with trocar tip design; review of literature and own results. J Lap- aroendosc Adv Surg Tech A 9 : 135-140, 1999

7) Azurin DJ, Go LS, Arroyo LR, et al : Trocar site herniation following laparoscopic cholecystectomy and the significance of an incidental preexisting umbilical hernia. Am Surg 61 : 718-720, 1995

8) Kadar N, Reich H, Liu CY, et al : Incisional hernias after major laparoscopic gynecologic procedures. Am J Obstet Gynecol 168 : 1493-1495, 1993

9) Bergemann JL, Hibbert ML, Harkins G, et al : Omental herniation through a $3-\mathrm{mm}$ umbilical trocar site : unmasking a hidden umbilical hernia. J Laparoendosc Adv Surg Tech A 11 : 171-173, 2001

10) Bhoyrul S, Mori T, Way LW : Radically expanding dilatation: A superior method of laparoscopic trocar access. Surg Endosc 10 : 775-778, 1996

11) Boldò E, Perez de Lucia G, Aracil JP, et al : Trocar site hernia after laparoscopic ventral hernia repair. Surg Endosc 21 : 798-800, 2006

12) Palanivelu C, Rangarajan M, Senthilkumar R, et al : Laparoscopic management of drain-site incisional hernias following laparotomies-a simple suture technique. J Laparoendosc Adv Surg Tech A 17 : 331334,2007 